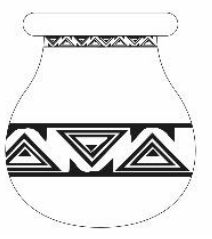

\title{
A INDESTRUTIBILIDADE DO SER NA FILOSOFIA DE ARTHUR SCHOPENHAUER
}

\author{
Maria Valéria da Silva de Freitas ${ }^{1}$
}

Resumo: O presente texto traz uma breve abordagem sobre a morte e a questão da indestrutibilidade do Ser a partir de uma análise da obra $O$ mundo como Vontade $e$ Representação, do filósofo Arthur Schopenhauer (1788-1860) e outros textos de apoio. Schopenhauer aborda a morte como natural, intrinsicamente ligada a vida, e que a mesma não é um mal para o homem e nem representa perigo para a espécie humana, por isso, não deveríamos temê-la, mas encará-la com serenidade, visto que a morte não é o fim absoluto, mas apenas o retorno do indivíduo para a natureza. O filósofo pontua que o Ser é indestrutível e que, após a morte, permanecerá presente por meio da vontade nos seres que continuam vivos. O que se perde com a morte é apenas a individualidade; a matéria, jamais a essência do Ser. Cada Ser que morre, nasce um novo em uma matéria diferente, porém com a mesma essência do que se fora, por isso o Ser em si, e por essência, não morre por ser indestrutível. Desta forma, o homem não pode viver sem pensar na morte, sendo necessário refletir sobre a finitude para viver o presente, sendo que é apenas no presente que a vontade se manifesta.

Palavras-chave: Arthur Schopenhauer. Morte. Ser. Vontade.

\begin{abstract}
This essay presents a brief approach on death and the Indestructibility of the Being, basing itself on an analyzes of Th860), ane World as Will and Representation, written by the philosopher, Arthur Schopenhauer (1788-1d others support works. Schopenhauer discusses death as a natural phenomenon, intrinsically related to life, and which it is not harmful to the man, neither it represents a threat to the human species. Knowing this, death should not frighten us, instead, we should face it with tranquility since death is not the absolute end, but only the return of the individual to nature. The philosopher punctuates that the Being is indestructible and, after death, it remains among, through the will-to-live, inside of those who remain alive. What it is lost with death is only the individuality, the matter never the Being's essence. Each Being that dies is reborn anew as a different matter, but with the same essence of the one that died, and so does not die because it is indestructible. This way, the man cannot live without thinking about death, it is necessary to reflect upon the finitude to live the present, as it is only in the present that the will-to-live manifest itself.
\end{abstract}

Keywords: Schopenhauer; Death; Being; Will-to-live.

\footnotetext{
${ }^{1}$ Graduada em Licenciatura Plena em Filosofia pela Universidade do Estado do Pará-UEPA, cursando a Licenciatura em Ciências Sociais Aplicadas pela Universidade do Estado do Pará-UEPA. Emailmvalfreitas2016@gmail.com
} 


\section{REVISTA APOENA - Per. dos Dis. de Fil. da UFPA \\ Belém, 2019, V. 1, N.1.}

\section{Introdução}

O presente texto traz uma breve abordagem sobre a indestrutibilidade do Ser a partir da análise da obra $O$ mundo como Vontade e Representação, do filósofo Arthur Schopenhauer (1788-1860). Schopenhauer é considerado um pensador pessimista e radical por dizer que vivemos no pior dos mundos possíveis. Viveu em meados do século XIX, e não é um dos mais populares filósofos de tal século. Seu pensamento influenciou outros filósofos, artistas e escritores do século XX, como Nietzsche, Wagner, Tolstoi e outros. Schopenhauer viajou bastante para buscar, nas experiências do mundo, suas próprias conclusões acerca da pessoa humana e seus conflitos internos. Para ele, é com base na intuição empírica de mundo que podemos formular nosso conhecimento, deste modo Schopenhauer formula uma metafísica imanente.

Segundo Jair Barboza (2015), nessa viagem pelo mundo Schopenhauer pôde ver com os próprios olhos a condição miserável do ser humano, coletando vários relatos de pessoas em cidades como Lyon, extremamente atingidas pela Revolução Francesa. Ele não entendia o motivo das pessoas, apesar de terem sido diretamente atingidas pela Revolução, inclusive com a perda de familiares e amigos, ainda continuarem no mesmo local, palco das diversas atrocidades em que o ser humano é capaz. Partindo dessas observações ele futuramente criaria sua teoria do sofrimento, o qual, para ele, está diretamente ligado a condição humana.

Arthur foi fortemente influenciado pela teoria das Ideias de Platão ${ }^{2}$ e a coisa em si de $\mathrm{Kant}^{3}$. Sua teoria, apesar de autônoma e independente, dar-se-á, em alguns momentos de difícil entende-la se não houver a inserção de alguns conceitos-chave desses dois grandes filósofos, um Clássico e outro Moderno. Apesar de admira-los muitos Schopenhauer vai mais além ao dizer que a essência é vontade, sendo que, a mesma não se encontra em mundos além, mas na própria subjetividade dos indivíduos. Mas a noção de Ideia de Platão e de coisa em si do Kant foram extremamente importantes na concepção de sua teoria da vontade que, para ele, é a mesma coisa a qual falavam os dois.

A obra central de Arthur Schopenhauer é O Mundo como Vontade e Representação, concebida em 1818, dividida em quatro livros. Ele esperava encontrar a glória com tal obra, pois acreditava ter decifrado o enigma do mundo.

\footnotetext{
2 Platão (428-347 a. C) filósofo Grego, considerado um dos Clássicos da filosofia, para ele, o mundo é constituído pelas ideias (conhecimento do que é real verdadeiro) e aparências (ilusão, esse seria o mundo em que estamos inseridos, em contato pelos sentidos), já que o real só concebido pelo intelecto.

3 Kant, Immanuel (1724-1804), filósofo Alemão de grande influência, na formação do pensamento contemporâneo, sua filosofia teve grande influência na filosofia de Schopenhauer.
} 


\section{REVISTA APOENA - Per. dos Dis. de Fil. da UFPA \\ Belém, 2019, V. 1, N.1.}

Arthur faz uma viagem por um ano pela Itália, esperando na volta encontrar o reconhecimento, no entanto isso não aconteceu. O tão esperando reconhecimento só chegou bem tarde, após inúmeras tentativas, quando ele já tinha 63 anos de idade em 1851, após a publicação de Parerga e Paralipomena. Depois disso, muitas pessoas o importunavam em sua residência em Frankfurt, em Main, onde vivia apenas na companhia de seu cachorro Atma. Todos buscavam "conhecer o filósofo das dores e do sofrimento do mundo (assim como dos instantes em que eles são neutralizados)" (BARBOZA, 2015, p. 15).

Antes de sua morte, Schopenhauer é convidado a entrar para a Academia de Ciências de Berlim, porém recusa ao dizer ter vivido a vida toda, até então, sem honrarias, não seria agora que precisaria dela. Em 21 de setembro de 1860, Arthur Schopenhauer morre aos 72 anos de idade.

A obra magna desse filósofo é $O$ Mundo como Vontade e Representação, como foi dito anteriormente, e será analisada neste artigo, seguido de A Metafisica da Morte, que serve de prólogo das ideias concebidas por ele em sua obra magna. O objetivo é fazer uma análise sobre a morte e a indestrutibilidade do Ser a partir do exposto pelo filósofo.

Para Schopenhauer (2000), a morte é o tema mais importante da filosofia, a sua grande inspiradora, ela é pontapé inicial para se filosofar, pois sem ela, talvez, nunca se teria filosofado.

Para muitas pessoas, a morte é o maior dos males da humanidade, para outros, não deveria existir por ser oposta à vida, desta forma, elas evitam tratar a questão da morte por causar-lhes angústia, dor e medo. Por fim, para estes indivíduos, pensar a morte pode atrair coisas ruins como a própria morte, deste modo, a sua maioria evita falar do tema.

Arthur Schopenhauer busca desmistificar essa ideia que se tem sobre a morte, e vem por meio de sua filosofia nos mostrar que ela não é um mal e também não representa nenhum perigo para a espécie humana, portanto, não deveríamos temê-la, mas encará-la com serenidade, visto que a morte não é o fim absoluto, mas apenas o retorno do indivíduo para o ventre da natureza, ou seja, o indivíduo estará apenas retornando para onde esteve um dia. A vida é apenas uma pequena passagem comparado ao que fora antes e será depois da morte, isto nos remete ao présocrático Empédocles ao dizer: "Não há nascimento para nenhuma das coisas mortais; não há fim pela morte funesta; há somente mistura e dissociação dos componentes da mistura. Nascimento é apenas um nome dado a esse fato pelos homens" (EMPÉDOCLES apud SOUZA, 1996 , p. 27$)^{4}$.

\footnotetext{
${ }^{4}$ SOUZA, /.../ Os pré-socráticos. Ed: Nova Cultural Ltda., São Paulo,1996.
} 


\section{REVISTA APOENA - Per. dos Dis. de Fil. da UFPA \\ Belém, 2019, V. 1, N.1.}

Schopenhauer coloca que a morte não pode ser o fim, por ser apenas uma ilusão da vontade que é a essência íntima do Ser, e indestrutível, inabalada pela morte, deste modo, o Ser verdadeiro permanecerá para sempre no presente onde a vida for possível.

\section{A indestrutibilidade do Ser na filosofia de Arthur Schopenhauer}

O ser humano desde sempre se questionou sobre a morte, por ser cercada de mistérios que nunca foram desvendados e provavelmente nunca serão, como bem coloca Sigmund Freud em sua obra $O$ futuro de uma Ilusão. O primeiro filósofo a dar atenção especial ao tema da morte foi Platão, como coloca Scarlet Marton ${ }^{5}$ em Morte como instante de vida. Segundo ela, Platão usou a morte do mestre Sócrates para falar do fenômeno. Sócrates descreve a morte como sendo algo bom, porque ela liberta a alma de sua prisão o corpo, e a vida, segundo ele, é apenas uma experiência da alma que com a morte estará livre. A vida, para Sócrates, é um longo aprendizado sobre a morte e o filósofo verdadeiro deve se ocupa com esta questão ao longo de sua vida.

Para Schopenhauer (2000), a morte é a questão mais importante da filosofia, ele busca mostrar que ela é algo natural e que não devemos temê-la porque após a sua chegada não existirá dor ou sofrimento, o indivíduo apenas deixará de existir enquanto matéria.

A morte deve ser encarada com serenidade como mostrou Sócrates, que se manteve calmo até seus últimos momentos. Na obra Apologia de Sócrates, que relata os momentos finais da vida do filósofo, em uma de suas últimas frases, dita quando já estava bebendo a cicuta, Platão mostra como o mestre se manteve firme e sereno diante de sua morte, esclarecendo isto através de tais palavras: "mas está na hora de nós irmos: eu para morrer; vós para viver. A quem tocou melhor parte, é o que nenhum de nós pode saber, exceto a divindade" (PLATÃO,1980, p. 72 de).

A morte é um mistério e sobre ela não há o que falar e, como já advertia Epicuro ${ }^{6}$, ela não é nada para nós, já que quando existimos ela não existe e quando ela existir, nós já não mais existimos.

Então, o mais terrível de todos os males, a morte, não significa nada para nós, justamente porque, quando estamos vivos, é a morte que não está presente, ao contrário, quando a morte está presente, nós é que não estamos. A morte, portanto, não é nada, nem para os vivos, nem para os mortos, já que para aqueles ela não existe, ao passo que estes não estão mais aqui (EPICURO, 2002, p. 29).

\footnotetext{
5 MARTON, Scarlett. Morte como instante de vida. 2010. Extraído em 29 de março de 2018 do site http://historianovest.blogspot.com/2010/02/morte-como-instante-de-vida.html.

${ }^{6}$ Epicuro de Samos (341-271 a. C.) foi um filósofo grego do período helenístico. Seu pensamento foi muito difundido em numerosos centros epicuristas que se desenvolveram na Jônia, no Egito e, a partir do século I, em Roma, onde Lucrécio foi seu maior divulgador.
} 


\section{REVISTA APOENA - Per. dos Dis. de Fil. da UFPA \\ Belém, 2019, V. 1, N.1.}

O indivíduo é apenas aparência representação, perante nossos olhos o homem nasce e morre. A vida e a morte são coisas que existem e está fora do nosso alcance tentar alterá-las, são dois acidentes e nós somos apenas expectadores. Assim, o indivíduo deve enxergar esses acidentes filosofando, ou seja, deve entender que é apenas um fenômeno passageiro. Nesse sentido, Schopenhauer adverte:

Nascimento e morte, dois acidentes que pertencem igualmente à vida; eles equilibramse; são mutuamente a condição um do outro, ou, caso se prefira esta imagem, são os polos desse fenômeno, a vida, tomada como conjunto[...] (SCHOPENHAUER, 2001, p. 289).

O filósofo Martin Heidegger ${ }^{7}$, conforme citado em Reale \& Antiseri (1991), em seu livro Ser e Tempo, coloca que dentre as muitas possibilidades do indivíduo, a morte é a diferente de todas, pois pode-se escolher o que se quer ser, o que se quer fazer, mas não se pode deixar de morrer. "A morte é a possibilidade que torna impossível todas as outras." (HEIDEGGER, apud REALE \& ANTISERI,1991 p. 586).

Para Heidegger, entender a morte como limite final da existência e se preparar para ela sem deixar de viver a vida é viver de forma autêntica. O homem é um Ser para a morte e, compreendendo isso, ele se torna um Ser autêntico e a morte já não o atormenta mais. Porém, se o indivíduo é um Ser que teme a morte, que não tem coragem de refletir sobre ela, vive, segundo Heidegger, uma vida inautêntica, e, como dizia Platão, "uma vida irrefletida não vale a pena ser vivida". O indivíduo se pega em projetos e questões e se esquece da morte, sendo que é de fundamental importância pensar a morte para se ter uma vida autêntica.

Schopenhauer (2001) coloca que a vida é uma queda perpétua na morte e pelo simples fato de termos nascido já lhe pertencemos. A cada Ser que morre, nasce um novo em uma matéria diferente, porém com a mesma essência do que já se fora, por isso, o Ser em si e por essência não morre, mas permanece em cada Ser que nasce. O que perece com o fim do fenômeno individual é a consciência, pela qual a vontade se manifesta, porém, a vontade permanece porque é a coisa em si, enquanto a consciência acrescentada ao nascer perece com a morte, sendo, por isso, distinta da vontade de viver que é a essência.

Segundo Schopenhauer, a morte é o sono que o indivíduo tem todos os dias, porém, no sono há possibilidade do despertar, já a morte é a perda da individualidade, ou seja, ela é o sono sem o despertar, "todo o resto do ser terá o seu despertar, ou antes, ele não deixou de estar acordado". (SCHOPENHAUER, 2001, p. 292).

\footnotetext{
${ }^{7}$ Heidegger, Martin (1989-1976), foi um filósofo com grande importância e influência do sec. XX, e seu legado filosófico continua muito atual, sua mais importante obra é Ser e Tempo (1927).
} 


\section{REVISTA APOENA - Per. dos Dis. de Fil. da UFPA \\ Belém, 2019, V. 1, N.1.}

O sono da morte é tão longo enquanto o da vida é tão curto, por isso, não se deve perder tempo amarrado ao passado, ao que não tem mais volta e nem tentar viver no futuro, pois isso é impossível, mas viver o presente, que é a única coisa que existe sempre, e até ele um dia será passado. Mas não existe muita diferencia entre sono e morte, pois os dois não são um perigo para a natureza, visto que o Ser é indestrutível e irá despertar e continuará vivo em outro Ser.

O que se desfaz com a morte é apenas a matéria e a individualidade, assim a morte não representa nenhum perigo à espécie, mas ao indivíduo. Porém, a morte não é, para este, o fim absoluto, mas apenas o retorno para onde esteve um dia. A vida é apenas uma pequena passagem comparado ao que fora antes e será depois da morte.

Segundo Schopenhauer, se paramos para perguntar onde estão as futuras gerações, de onde vem, não percebemos, mas estão contidas em nós. Schopenhauer (2000) usa o exemplo das moscas que nascem pela manhã e morrem ao anoitecer e seus ovos dão origem a outras moscas no amanhecer do dia seguinte, tudo dura pouco: as moscas, momentos, os animais e o homem, alguns anos. Tão logo perecem na morte, porém a espécie continua.

Schopenhauer coloca que, o homem é para a natureza seu fim último, e o seu objetivo é a conservação deste, seguindo isto, vem a propagação da espécie, a vontade manifesta na natureza. Tendo o indivíduo feito tal ação para a natureza, ela o abandona, deixando-o exposto a todos os tipos de perigo, sozinho, desamparado, assistindo de perto seus temores, mantendose indiferente frente a morte do Ser individual, pois o que realmente interessa para a natureza é a conservação da espécie.

Deve-se encarar a morte com naturalidade, assim como se aceita a vida, pois a mesma não é nenhum mal, nem a aniquilação do Ser, independe do pavor que ela cause, é apenas um fenômeno da natureza que faz parte da vida desde o instante em que nascemos. O Ser verdadeiro não acaba com a morte, ele é indestrutível, “[...] o Ser vivente não sofre com a morte nenhuma aniquilação absoluta, mas continua a subsistir em e com toda a natureza”. (SCHOPENHAUER, 2000, p. 77).

Deste modo, após a morte, o Ser continua, pois é a natureza, está nela assim como ela está nele, ou seja, o indivíduo é um microcosmo fazendo parte do macrocosmo. Schopenhauer (2001) diz que os animais vivem na natureza como sendo parte dela e estão para ela, sem consciência alguma de que vão morrer em algum momento de sua existência, pois apenas o homem tem, por sua consciência, certeza de que irá morrer.

$\mathrm{Na}$ morte não há dor e nem sofrimento, a vida que é constituída de tais características, enquanto ela existir iremos sofrer, pois estamos expostos a todos os tipos de perigos, ela é uma luta constante pela existência, com uma certeza de que, a qualquer momento, seremos vencidos 
pela morte. Vivemos para a morte, ela é nossa única certeza, a adiamos a cada caminhar, respirar, bater do coração, porém, ela não por ser evitada e chegará para todos nós a qualquer momento, enfim, a vida é uma queda perpétua na morte.

Schopenhauer (2001) recorre à ideia de Platão para explicar que o Ser verdadeiro é indestrutível, morrendo apenas a representação individual, não a ideia de homem, ou seja, a espécie. Um cão, por exemplo, que está diante de nós, para nascer, muitos outros tiveram que morrer, porém, com eles não morreu a ideia de cão, o Ser verdadeiro presente naquele novo cão. Assim é com a espécie humana, na medida em que morrem vários seres, nascem outros para dar continuidade à existência, deste modo a natureza se mantem equilibrada, o Ser em si continua desperto nesses novos seres. Schopenhauer diz que só é possível entender tal questão por meio da metafísica.

O terror da morte, segundo Schopenhauer, também é pelo fato de o indivíduo pensar que vai morrer enquanto o mundo continua, porém o que acontece é o oposto, é o mundo que se acaba, enquanto ele, por essência, continua, o mundo era para ele apenas representação, no qual sua vontade se manifestava através de um corpo orgânico que com a morte se degenera. "O fim da pessoa é tão real quanto era o seu começo; e no mesmo sentido em que não éramos antes do nascimento, não seremos depois da morte [...]" (SCHOPENHAUER, 2000, p. 116).

Segundo Schopenhauer (2001), o medo da própria destruição é a priori ${ }^{8}$, e intato tanto no homem como no animal, embora o animal não conheça a morte, possui este temor, que já vem justo de todo Ser que nasce, é por causa desse temor que mesmo sem ter consciência da morte, os animais tentam proteger sua prole diante de uma ameaça de morte, faz isso porque é "pura vontade de vida", o homem é exatamente desta forma, a maior ameaça para si e para o outro é a morte e nada o deixa mais angustiado, mas este apego à vida independe do conhecimento, por isso é a priori.

Esse apego à vida é irracional, nosso Ser em si mesmo é vontade de vida, mesmo que esta seja só dor e sofrimento, o indivíduo quer viver, e a vontade é totalmente irracional, cega, então este apego pela vida não provém do conhecimento, porque “o conhecimento, ao contrário, bem longe de ser a origem do apego à vida, atua até contra este, na medida em que desvela a ausência de valor da mesma e, assim, combate o temor da morte" (SCHOPENHAUER, 2000, p. 64).

Temos medo da morte não necessariamente pela dor, visto que, dor e morte são diferentes, e muitas vezes o indivíduo busca a morte para fugir da dor, como nos casos de eutanásia, por

\footnotetext{
${ }^{8}$ A esse termo Kant se refere aquilo que é puro que não tem relação alguma com a experiência.
} 
exemplo. Mas então do que temos medo? Nosso medo é da não-existência, ou do que pode acontecer após a morte, ou seja, o indivíduo é contagiado pelo senso comum e tem medo de refletir filosoficamente acerca daquilo ao qual não pode fugir. O temor da morte não provém do conhecimento, mas sim da vontade, sendo que, segundo Schopenhauer, caso o homem fosse um Ser que conhece, a morte não seria nada para ele, e o mesmo até ficaria indiferente em relação a ela. O conhecimento que adquirimos por meio do intelecto se finda com a morte, porém a vontade permanece eterna, infinita.

"A consciência é a vida do sujeito do conhecimento, ou do cérebro, e a morte é o seu fim. Por conseguinte, a consciência é finita, sempre nova, começando a cada vez. Só a vontade permanece e também só a ela concerne a permanência, pois ela é a vontade de vida[...]" (SCHOPENHAUER, 2000, p. 125).

Para Schopenhauer (2001), o indivíduo se desespera por saber que vai morrer e por ter a falsa ilusão que vai deixar de existir, porém não sabe ele que ele próprio é o senhor da existência, por que ele está em tudo, em todas as coisas, é a essência, é indestrutível, nunca inabalado pela morte.

A espécie, segundo o filósofo, é o único modo de o indivíduo superar a morte, pois a vontade de viver continua, por toda parte, deste modo, a vida é em si poderosa e indestrutível, mas o individuo não consegue ver isso enquanto a vontade estiver com a visão encoberta pelo véu da ilusão que permite que ela se veja apenas de forma individual, mas ao se reconhecer no todo, ela, através do conhecimento, se manterá mais serena em relação a morte.

\section{Considerações Finais}

Schopenhauer, em sua obra $O$ mundo como vontade e como representação, busca mostrar a morte de uma perspectiva metafísica, colocando que ela não deve ser banalizada ou tida como o pior dos males da humanidade, visto que, a mesma é para o homem apenas o fim fenomenal dentro do espaço temporal, mas jamais o fim deste por essência, pois ela, que é a vontade de vida, existe dentro e fora do tempo. Dessa forma, o indivíduo continuará a existir por meio desta em toda a natureza.

Para Schopenhauer (2001), a preocupação dos indivíduos deverá ser sempre com o momento presente, pois é preciso reconhecê-lo e vivê-lo, pois, fora deste, não há vida, e, antes dele, é apenas passado que não existe mais, depois, só resta a morte daquilo que já foi um dia e que nela não será mais.

O princípio de vida, para Schopenhauer, é tido pelo homem como um sentimento que está contido nele, o mesmo consequentemente acaba se tornando imperecível e indestrutível, visto 
que o mesmo é vontade de vida. Essa vontade que tem no homem, através do seu corpo, seu puro reflexo, que é manifesta nele de maneira cega e irracional e que subsiste através da espécie, e que, portanto, nas novas gerações, estarão contidas a vontade de vida, que, por intermédio da procriação da espécie, assegurou sua existência.

O Ser, enquanto ideia, será sempre o mesmo em qualquer época, pois, por meio da espécie, continua eternamente, é perecível apenas enquanto fenômeno, isso tanto aos homens quantos aos animais. Assim, a vontade de vida se assegura intacta, sempre renovada a cada novo ser que nasce, e a morte, de forma alguma, atinge o Ser na sua ideia, pois através dessa o Ser permanece indestrutível. E a morte, nesse sentido, é apenas uma ilusão da individualização.

O trabalho em questão buscou mostrar a importância de se refletir sobre a finitude, mostrando, dentro da concepção schopenhauriana, que a mesma não representa nada para o indivíduo enquanto essência, visto que esta é eterna e indestrutível, desse modo, com a morte do corpo, ou seja, do fenômeno individual, o Ser continua a intacto por todo lugar onde houver vida.

\section{REFERÊNCIAS BIBLIOGRÁFICAS}

BARBOZA, Jair. Schopenhauer: a decifração do enigma do mundo / Jair Barboza. - São Paulo: Paulus, 2015. - (Coleção como ler filosofia).

EPICURO, Carta sobre a felicidade: (a Meneceu) / Epicuro; Tradução e apresentação de Alvaro Lorencini e Enzo Del Carratore. - São Paulo: Editora UNESP, 2002.

FREUD, Sigmund. O futuro de uma ilusão / Sigmund Freud; tradução de Renato Zwick; revisão técnica e prefacio de Renata Udler Cromberg; ensaio bibliográfico de Paulo Endo \& Edson Sousa. - Porto Alegre, RS: L\&PM, 2011. [Coleção L\&PM Pocket; v. 849].

MARTON, Scarlett. Morte como instante de vida. 2010. Extraído em 29 de março de 2018 do site http://historianovest.blogspot.com/2010/02/morte-como-instante-de-vida.html.

PLATÃO. Diálogos: Apologia de Sócrates. Tradução de Carlos Alberto Nunes. Editora: Universidade Federal do Pará, 1980.

REALE, Giovanne. História da Filosofia: do romantismo até nossos dias / Giovane Reale, Dario Antiseri; - São Paulo: Edições Paulinas, 1991. - (coleção filosofia) 
SCHOPENHAUER, Arthur. Metafísica do Amor, Metafisica da morte; Tradução Jair Barbosa; revisão técnica Maria Lucia Mello Oliveira Cacciola. - são Paulo: Martins fontes, 2000. (Clássicos).

SCHOPENHAUER, Arthur. $O$ Mundo como Vontade $e$ Representação. Rio de Janeiro: ed: contraponto, 2001.

SOUZA. Os pré-socráticos. Ed: Nova Cultural Ltda., São Paulo,1996. 